\title{
Improving the Direct Electron Transfer in Monolithic Bioelectrodes Prepared by Immobilization of FDH Enzyme on Carbon-Coated Anodic Aluminum Oxide Films
}

\author{
Alberto Castro-Muñiz ${ }^{1 *}$, Yasuto Hoshikawa ${ }^{1}$, Hiroshi Komiyama ${ }^{1}$, Wataru Nakayama ${ }^{1}$, \\ Tetsuji Itoh ${ }^{2}$ and Takashi Kyotani' \\ ${ }^{1}$ Institute of Multidisciplinary Research for Advanced Materials, Tohoku University, Sendai, Japan, ${ }^{2}$ National Institute of \\ Advanced Industrial Science and Technology (AIST), Sendai, Japan
}

\section{OPEN ACCESS}

Edited by: Santosh Kumar Yadav, Drexel University, USA

Reviewed by: Qihui Wu,

Quanzhou Normal University, China Yogendra Kumar Mishra, Univesity of Kiel, Germany

*Correspondence: Alberto Castro-Muñiz alberto@tagen.tohoku.ac.jp

Specialty section: This article was submitted to Carbon-Based Materials, a section of the journal

Frontiers in Materials

Received: 15 December 2015 Accepted: 26 January 2016 Published: 10 February 2016

Citation:

Castro-Muñiz A, Hoshikawa Y, Komiyama $H$, Nakayama W, Itoh T and Kyotani T (2016) Improving the Direct Electron Transfer in Monolithic

Bioelectrodes Prepared by Immobilization of FDH Enzyme on Carbon-Coated Anodic Aluminum Oxide Films.

Front. Mater. 3:7.

doi: 10.3389/fmats.2016.00007
The present work reports the preparation of binderless carbon-coated porous films and the study of their performance as monolithic bioanodes. The films were prepared by coating anodic aluminum oxide films with a thin layer of nitrogen-doped carbon by chemical vapor deposition. The films have cylindrical straight pores with controllable diameter and length. These monolithic films were used directly as bioelectrodes by loading the films with D-fructose dehydrogenase $(\mathrm{FDH})$, an oxidoreductase enzyme that catalyzes the oxidation of D-fructose to 5-keto-D-fructose. The immobilization of the enzymes was carried out by physical adsorption in liquid phase and with an electrostatic attraction method. The latter method takes advantage of the fact that FDH is negatively charged during the catalytic oxidation of fructose. Thus, the immobilization was performed under the application of a positive voltage to the carbon-coated AAO film in a FDH-fructose solution in Mcllvaine buffer ( $\mathrm{pH}$ ) at $25^{\circ} \mathrm{C}$. As a result, the FDH-modified electrodes with the latter method show much better electrochemical response than that with the conventional physical adsorption method. Due to the singular porous structure of the monolithic films, which consists of an array of straight and parallel nanochannels, it is possible to rule out the effect of the diffusion of the D-fructose into the pores. Thus, the improvement in the performance upon using the electrostatic attraction method can be ascribed not only to a higher uptake but also to a more appropriate molecule orientation of the enzyme units on the surface of the electrodes.

Keywords: carbon-coated aluminum oxide film, FDH, enzyme immobilization, enzymatic electrode, direct electron transfer

\section{INTRODUCTION}

Electrodes modified with redox enzymes have been used as quick responsive biosensors with high accuracy and selectivity of a specific substrate and, more recently, as electrodes in enzymatic biofuel cells, i.e., a particular type of biofuel cells in which different oxidoreductase enzymes work as electrocatalysts. The oxidation and reduction of the substrates are catalyzed by the enzymes and the 
electrons are transferred between the enzymes and the surface of the electrodes on which the enzymes are immobilized. Usually, because redox sites are deeply embedded into the framework structure of the enzymes, the electron transfer has to be helped by mediators, such as redox compounds or redox polymers, which act as relays of electrons between the enzymes and the electrodes. This mediated electron transfer (MET) type of electrode requires the use of complicated processes, e.g., in the case of the enzymatic biofuel cells, compartmentalized cells are needed to avoid the crossover of the mediators between the anode and the cathode compartments. Besides, the mediators are usually expensive and toxic (Willner et al., 2009). If the redox sites are close to the electrode surface, electrons can be transferred to the surface directly thanks to the tunnel effect. This direct electron transfer (DET) type of electrodes has been extensively studied as electrodes for non-compartmentalized enzymatic biofuel cells, especially in the last years. Due to the especial structure requirement for enzymes, just a few enzymes can perform the DET. Among these, one of the most commonly used enzymes in bioelectrodes is D-fructose dehydrogenase $(\mathrm{FDH})$ that can catalyze the oxidation of $\mathrm{D}$-fructose to 5-keto-D-fructose with very high specificity (Ameyama et al., 1981). The FDH-modified electrodes are, therefore, very convenient bioanodes for fructose detection in electrochemical biosensors and biofuel cells.

In principle, the only properties required to the bioelectrodes are a large area and a good conductivity, such as metallic nanoparticles. Carbon materials are also very suitable thanks to both of those properties as well as their biocompatibility keeping the activity of enzymes. In the last years, a large number of carbon materials have been tested as bioelectrodes (Lim et al., 2007; Rubenwolf et al., 2010; Tsujimura et al., 2010; Flexer et al., 2011; Hamano et al., 2012; Filip and Tkac, 2014), particularly as FDH supports for biofuel cells anodes (Kamitaka et al., 2007; Wu et al., 2009, 2013; Miyake et al., 2011, 2013; Haneda et al., 2012), and these researchers have obtained promising results in terms of the power delivery. However, the power density in the enzymatic DET biofuel cells is still rather low. One way to improve the performance of carbon materials as FDH-modified electrodes is to increase the amount of enzymes immobilized in the bulk of the electrodes. However, a higher uptake of enzymes does not guarantee a better performance because other factors such as the accessibility of the substrate to the immobilized enzymes and the distance from the enzymes to the collector surface play a key role. For the latter issue, a simple contact between the enzymes and the electrodes might not be enough and it would also be necessary to shorten the distance between the redox site in FDH and the electrode surface to facilitate the transfer of electrons. This implies that one must be able to control the orientation of the FDH units as biomacromolecules on the surface, and such control has indeed been reported to be very important in order to achieve the DET between the enzymes and the current collector (Tominaga et al., 2007).

In the present work, we show a simple way to control the molecular orientation of FDH units on the carbon electrodes and demonstrate how the orientation control is crucial to improve the performance of FDH-modified carbon porous electrodes. Commonly, carbon porous materials have intricate pore structures that hinder the access of the substrates to the enzymes, so that it is very difficult to extract the sole effect of the orientation. For this motive, we decided to use an anodic aluminum oxide (AAO) film coated with a thin layer of carbon as a support for the enzymes. The continuous carbon-coated AAO (CAAO) film can function as a monolithic and binderless electrode, being regarded as a fully new type of carbon electrode for biofuel cells. Since an AAO film consists of straight, parallel pores with a uniform size in the range of the meso-macropores, the accessibility of the reactants inwards and outwards the electrodes would not be an issue. Here, the carbon-coated films were loaded with FDH and they were tested as electrodes by monitoring the current produced by the oxidation of fructose through the catalysis of the enzymes immobilized on the pore surface.

\section{MATERIALS AND METHODS}

\section{Sample Preparation AAO Films}

Anodic aluminum oxide films were prepared using the two-step anodization process (Masuda and Fukuda, 1995; Li et al., 1998). The surface of a high purity aluminum plate $(50 \mathrm{~mm} \times 50 \mathrm{~mm}$, Nilaco Corp.) was thoroughly cleaned and electro-polished in a perchloric and ethanol solution $\left(\mathrm{HClO}_{4}: \mathrm{EtOH}\right.$ ratio: 1:9 wt.) at $5^{\circ} \mathrm{C}$ by applying $20 \mathrm{~V}$ between the $\mathrm{Al}$ plate and a nickel plate for $10 \mathrm{~min}$. The electro-polished plate (Figure 1A) was then set to a homemade electrochemical cell in $0.3 \mathrm{M}$ oxalic acid at $15^{\circ} \mathrm{C}$ or $0.5 \mathrm{M}$ phosphoric acid at $10^{\circ} \mathrm{C}$ and the anodization was carried out under potentiostatic conditions by applying 40 and $160 \mathrm{~V}$ between the electro-polished $\mathrm{Al}$ plate and another pristine $\mathrm{Al}$ plate in the oxalic acid and phosphoric acid solutions, respectively. The first anodization was carried out for $1 \mathrm{~h}$, during which a thin oxide layer was formed on the Al plate surface. This first alumina layer was dissolved by chemical etching using a mixture of phosphoric acid (6 wt.\%) and chromic acid (1.8 wt.\%) at $60^{\circ} \mathrm{C}$. The second anodization was performed under the same conditions as in the first step but with an anodization time of 13 and $15 \mathrm{~h}$ for the oxalic acid and phosphoric acid electrolytes, respectively (Figure 1B). Afterwards, the plates were cut in ca. $10 \mathrm{~mm} \times 10 \mathrm{~mm}$ and the remaining $\mathrm{Al}$ that was not oxidized was dissolved by a selective chemical etching, where the squares were soaked in a $5 \mathrm{wt} . \%$ $\mathrm{CuCl}_{2}$ aqueous solution, to obtain a thin film with pores that are closed in the bottom side (Figure 1C). This barrier layer was removed by soaking the films in $1 \mathrm{M} \mathrm{H}_{3} \mathrm{PO}_{4}$ solution at $30^{\circ} \mathrm{C}$ for $60 \mathrm{~min}$ and, finally, AAO films with an array of hexagonal straight pores open on both sides were obtained (Figure 1D).

\section{Carbon-Coated AAO Films}

The AAO films were coated with a thin layer of carbon by means of chemical vapor deposition (CVD), in a tubular horizontal quartz reactor, using two different sources, acetonitrile vapor and acetylene gas at $800^{\circ} \mathrm{C}$ for $4 \mathrm{~h}$ and $600^{\circ} \mathrm{C}$ for $3 \mathrm{~h}$ respectively. The films were annealed beforehand by heating them up to $950^{\circ} \mathrm{C}$ for $1 \mathrm{~h}$ in air (see Figure S1 in Supplementary Material). After cooling down to room temperature, the films were heated up to the CVD temperature at a heating rate of $10^{\circ} \mathrm{C} / \mathrm{min}$ under a nitrogen 


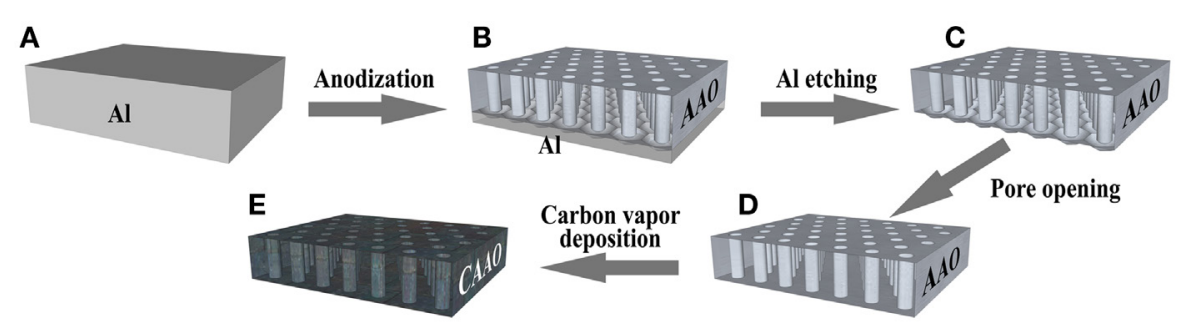

FIGURE 1 | Scheme of the preparation of the carbon-coated anodic aluminum oxide films. (A) A polished Al foil, (B) an anodic aluminum oxide (AAO) film on the Al substrate, (C) an AAO film, (D) an AAO film with pores open on both sides, and (E) a carbon-coated AAO film.

flow (400 $\mathrm{ml}(\mathrm{STP}) / \mathrm{min})$. Immediately after the reactor reached the target temperature, acetonitrile vapor or acetylene gas was introduced into the reactor. The acetonitrile vapor was generated by bubbling $\mathrm{N}_{2}$ through liquid acetonitrile in a saturator kept at $20^{\circ} \mathrm{C}$. The acetylene gas was diluted in $\mathrm{N}_{2}$ at $20 \mathrm{vol} . \%$ in a total flow of $400 \mathrm{ml}$ (STP)/min. After the CVD step, the films were heated at $1{ }^{\circ} \mathrm{C} / \mathrm{min}$ up to $900^{\circ} \mathrm{C}$ and the temperature was kept for $1 \mathrm{~h}$ under $\mathrm{N}_{2}$ flow with the aim of improving carbon crystallinity in order to increase the electric conductivity of the materials. The carbon-coated films (Figure 1E) were referred to as CAAO and CAAO-P for the ones prepared from the AAO films obtained with oxalic acid and phosphoric acid electrolytes, respectively.

\section{Characterization}

Scanning electron microscopy (SEM) studies were carried out with a Hitachi S4800 microscope. The transmission electron microscope (TEM) images were taken in a JEOL JEM-2010 at an acceleration voltage of $200 \mathrm{kV}$. The X-ray photoelectron spectroscopy (XPS) measurements were conducted in a JEOL JPS-9200 spectrometer operating under a pressure of $10^{-7} \mathrm{~Pa}$ with a $\mathrm{Mg} \mathrm{K} \alpha \mathrm{X}$-ray source using a power of $300 \mathrm{~W}$. XRD patterns were obtained with a Shimadzu XRD-6100.

D-fructose dehydrogenase from Gluconobactersp. was obtained from Toyobo enzymes. The concentration of FDH in McIlvaine buffer solution was estimated using the bicinchoninic acid (BCA) assay (Sigma-Aldrich BCA-1). The solutions used in this work were prepared using the as-received FDH lyophilized powder which contains $\sim 80 \%$ of stabilizers ${ }^{1}$. Thus, the real concentrations of FDH in the solutions are significantly lower than the concentrations calculated theoretically from the amount of as-received FDH powder. We, therefore, adopt the values measured by using the BCA assay as the concentrations in the solutions.

The electrochemical performance tests were carried out in a five-necked homemade three-electrode type cell (see Figure S3 in Supplementary Material). The counter electrode was a platinum coil and a Ag/AgCl-saturated $\mathrm{KCl}$ electrode (BAS Inc., Japan) was used as reference. All the potentials appeared hereafter will be referred to this reference, i.e., vs. $\mathrm{Ag} / \mathrm{AgCl}$. The working electrode was prepared by attaching a glassy carbon rod to a CAAO film using a conductive paste (Hitasol GA-715). A picture

${ }^{1}$ Toyobo-Enzymes. D-Fructose Dehydrogenase. Available at: http://www.toyobo. co.jp/seihin/xr/enzyme/j_top.html of a working electrode is shown in Figure S4 in Supplementary Material. The electrolyte, McIlvaine buffer solution ( $\mathrm{pH} 5$ ), was degassed before the electrochemical measurements by bubbling $\mathrm{N}_{2}$ for $30 \mathrm{~min}$. All the tests were carried out at $25^{\circ} \mathrm{C}$ in a VMP3 potentiostat from Biologic.

\section{RESULTS AND DISCUSSION}

\section{CAAO Electrodes Physicochemical Properties}

The SEM micrographs of the cross section of the CAAO films (see Figure 2A) show that the cylindrical-shaped pores run vertically through the films and both top and bottom sides are open (see Figures 2B-E). Under the conditions described in Section "Materials and Methods," the thickness of the films used in this study was ca. $70 \mu \mathrm{m}$. The pore diameter distributions of the films were determined with the SEM micrographs and thereby main pore sizes are found to be about 40 and $240 \mathrm{~nm}$ for the CAAO and CAAO-P films, respectively. When the alumina in the CAAO films was dissolved by HF washing, bundles of carbon nanotubes were left (see Figure S2 in Supplementary Material), indicating the uniform carbon coating on the whole pore walls in the AAO films. Moreover, the thickness of the deposited carbon layer was estimated to be between 7 and $9 \mathrm{~nm}$ for both CAAO and CAAO-P films by observing the resulting carbon nanotubes with TEM (see Figure S2 in Supplementary Material).

When acetonitrile was used as the carbon source for the CVD, the coating layer of carbon was doped with nitrogen. The XPS analysis reveals that the carbon layer is doped with nitrogen in an atomic ratio N/C of 0.060 (see Figure 3A). The nitrogen functionalities are mainly quaternary $(61 \%)$ with a high contribution of pyridinic nitrogen $(26 \%)$ and a low amount of oxidized nitrogen (13\%) (Pels et al., 1995; Casanovas et al., 1996). The C 1s peak of the acetonitrile CAAO films shows a broader shoulder at high bind energies than the one from the acetylene CAAO films (see Figure 3B) due to the presence of nitrogen atoms (Maldonado et al., 2006; Chen et al., 2010). Since the XPS surface analysis can detect even the AAO substrate below the thin carbon layer, the oxygen spectra give no reliable information on oxygen-containing functional groups on the carbon surface.

The electrolyte used in the adsorption of the enzymes as well as in the electrochemical performance tests was McIlvaine buffer solution. Thus, the wettability of the $\mathrm{N}$-doped and non-doped CAAO films to the solution was tested by placing a $5 \mu \mathrm{l}$ drop 


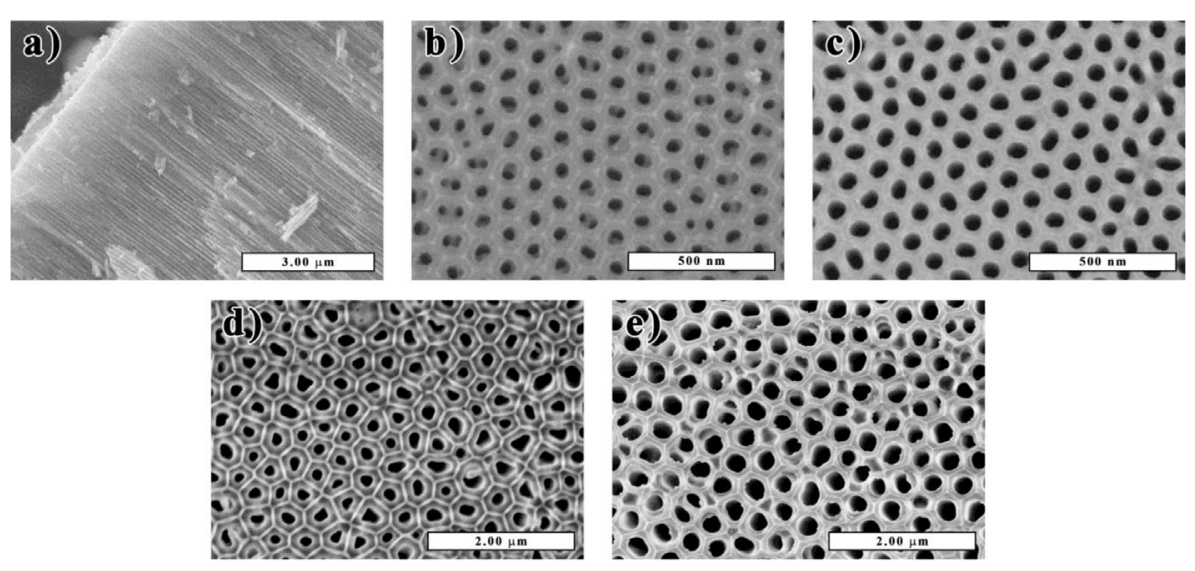

FIGURE 2 | SEM micrographs of the cross section (A) and bottom and top sides of the CAAO (B,C) and CAAO-P (D,E) films

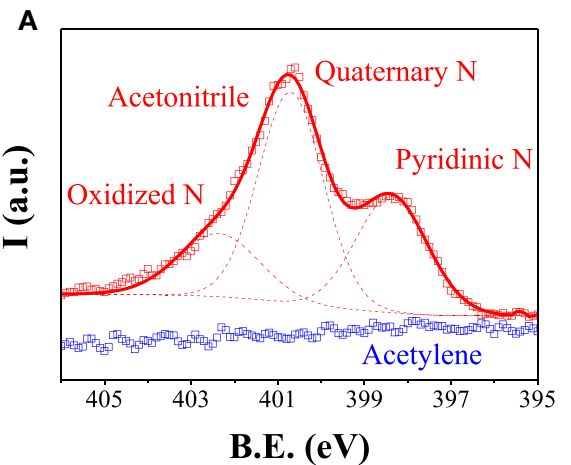

CAAO films as bioanodes

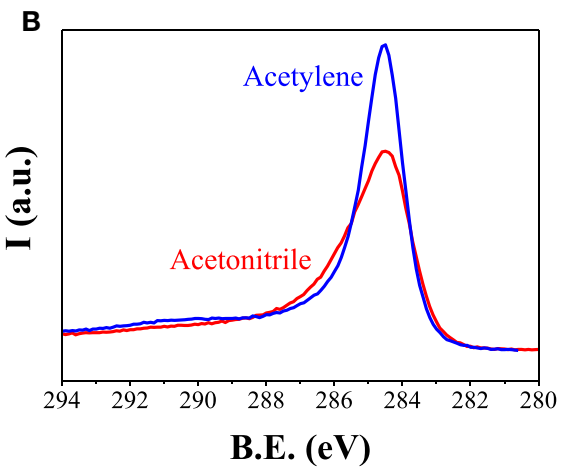

FIGURE 3 | XPS N 1s (A) and C 1s (B) spectra of N-doped (red) and non-doped (blue) CAAO films.

on the surface of the films. As shown in Figure 4, the presence of nitrogen on the carbon layer is beneficial for increasing the wettability to McIlvaine solution. The surface energy of the doped and non-doped CAAO films took values of 56 and $48 \mathrm{~mJ} / \mathrm{m}^{2}$, respectively (see Eq. S1 in Supplementary Material), i.e., even though both materials are hydrophobic, the presence of $\mathrm{N}$ increases the wettability of the films, thus, improving the affinity for the Mcllvaine solution. The N-doped CAAO films were, therefore, chosen for the following tests.

\section{Physical Adsorption of FDH on CAAO Film and Its Electrochemical Performance}

To use the CAAO films as bioanodes, the FDH enzymes have to be immobilized on the surface of the pores. As a first approach, the physical immobilization method in liquid phase was used. The CAAO films were soaked in McIlvaine buffer solutions (initial volume: $4 \mathrm{ml}$ ) with different initial concentrations of $\mathrm{FDH}$ enzyme $(184,371$, and $437 \mu \mathrm{g} F \mathrm{FH} / \mathrm{ml})$ at $\mathrm{pH} 5$ and $4^{\circ} \mathrm{C}$ under mild stirring. The amount of enzyme loaded inside the pores of the CAAO films was calculated from the amounts of FDH in the remaining solutions at different soaking times. The uptake of FDH on the films rapidly increases during the first 6 h (see Figure 5)
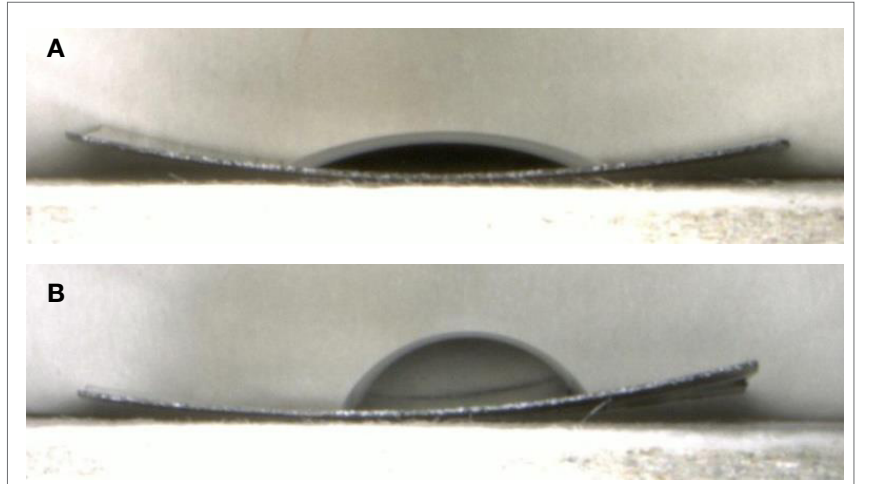

FIGURE 4 | Droplets of Mcllvaine buffer solution on $\mathrm{N}$-doped (A) and non-doped (B) CAAO films.

and then it almost levels off for all the FDH solutions. As expected, the more concentrated the initial FDH solution is, the higher the loading of enzyme into the pores of the CAAO films becomes.

Since the BCA quantification method requires taking $100 \mu \mathrm{l}$ aliquots of the solutions, their volumes sensitively decrease upon 


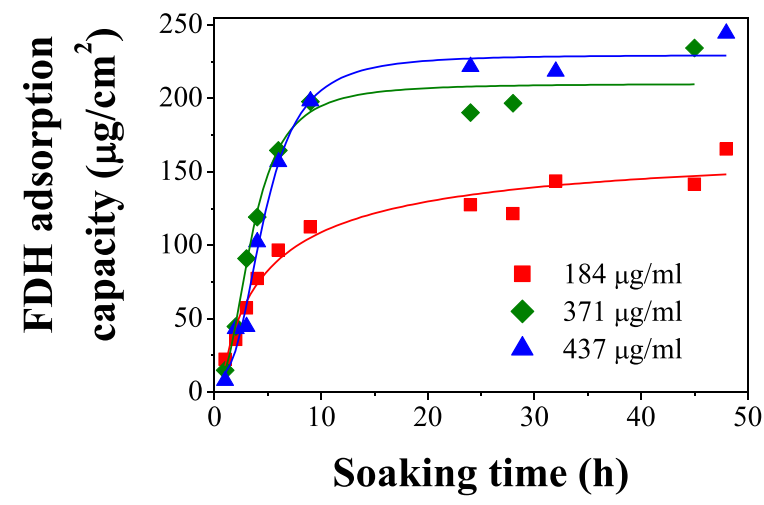

FIGURE 5 | Adsorption behaviors of FDH on CAAO films upon the soaking in Mcllvaine buffer solutions with different concentrations at $4^{\circ} \mathrm{C}$.

each measurement. After the first 24-48 h, some aggregation of the enzymes was observed in the solutions, making the measurements of the concentrations not accurate enough. For this reason, the soaking time was set to $15 \mathrm{~h}$ for the preparation of the electrodes in the following electrochemical performance tests and Figure 5 indicates that this soaking time is long enough to attain the maximum adsorption capacity. The adsorption capacities of FDH on the CAAO films were estimated to be 122, 204, and $221 \mu \mathrm{g} / \mathrm{cm}^{2}$ for the solutions with initial concentrations of 184,371 , and $437 \mu \mathrm{g} / \mathrm{ml}$, respectively.

The ideal adsorption of the enzymes would be the one where all the surface of the CAAO pores would be covered by a monolayer of FDH. In such a case, the electron transfer from the enzymes to the electrodes would be easily achieved. However, if the adsorption takes place in a multilayer fashion, the electrons would have to follow a too long path and the electron transfer would probably not take place as a result. Besides, if there is more than one layer of enzymes on the surface of the pores, they would hinder the access of fructose to the first layer of enzymes near the surface of the pores. In the case of monolayer adsorption, the amount of FDH loaded on the CAAO films can theoretically be calculated by using the diameter and length of the pores obtained by the SEM observation together with the reported size of one FDH enzyme unit, $7 \mathrm{~nm}$ (Tominaga et al., 2007). Assuming cylindrical pores in the CAAO films and spherical-shaped enzymes, the ideal uptake can be roughly estimated as ca. $1718 \mathrm{FDH} \mu \mathrm{g} / \mathrm{cm}^{2}$. The effectiveness of the physical adsorption method is, therefore, rather low. Besides, even if the initial concentration of $\mathrm{FDH}$ is further increased, the FDH units would tend to aggregate (Ameyama et al., 1981) instead of a monolayer adsorption due to hydrophobic attraction forces among the FDH units. In conclusion, the ideal adsorption would be very difficult to achieve with this method.

The enzyme-modified CAAO films prepared by the above physical adsorption method were washed with the buffer solution and then each film was set in the three-electrode cell described in Figure S3 in Supplementary Material filled with $10 \mathrm{ml}$ of McIlvaine buffer solution ( $\mathrm{pH}$ 5). As shown in Figure 6, the cyclic

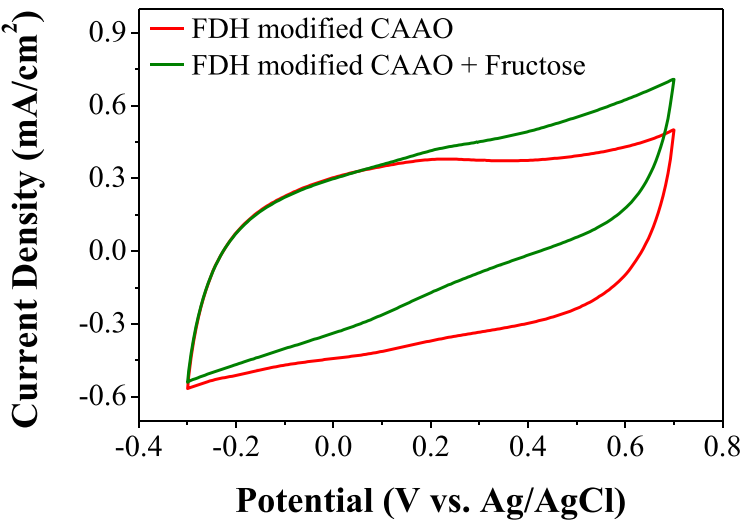

FIGURE 6 | Cyclic voltammograms of CAAO films loaded with FDH before and after the addition of $D$-fructose.

voltammogram $(\mathrm{CV})$ of the enzyme loaded CAAO film is fairly square, suggesting a good electrical conductivity. An aliquot of $3 \mathrm{M}$ D-fructose in McIlvaine buffer solution was then added to the electrolyte to get to a total concentration of $200 \mathrm{mM} \mathrm{D}$-fructose as electrolyte. An increase of the anodic current is observed in the CV pattern (see Figure 6) due to the oxidation of D-fructose to 5-keto-D-fructose catalyzed by $\mathrm{FDH}$ and the transfer of electrons to the CAAO film.

\section{Electrostatic Attraction FDH Immobilization}

With the aim of improving the performance of the CAAO electrodes, the FDH was immobilized using the electrostatic attraction method. Usually, this method takes advantage of the amphoteric character of enzymes, i.e., if the $\mathrm{pH}$ of the media is higher than the isoelectric point of the enzyme, it would be negatively charged (Lee et al., 2009) and then, if a positive potential is applied to the electrode, the enzymes would be attracted to it. In a previous study (Khan et al., 1991), this method was applied to the adsorption of FDH on glassy carbon electrodes, but the transfer of electrons was rather low due to the random orientation of the enzymes on the electrode surface. This may be because the negatively charged sites are randomly distributed on the whole surface of the FDH molecule. In this study, a different approach has been attempted for the first time to the best of our knowledge. A FDH enzyme is composed of the following three subunits: flavin, heme-c (see Figure 7), and a third one whose function is not clear (Tominaga et al., 2007). The oxidation of D-fructose to 5-keto-D-fructose takes place in the flavin subunit (Figure 7A) and the electrons are then transferred to the heme-c subunit (Figure 7B) where the DET takes place (Tominaga et al., 2007, 2009). During this process, the heme-c subunit is negatively charged. Hence, if a positive potential is applied to the electrode during the catalytic oxidation of $\mathrm{D}$-fructose, the enzyme units would be attracted to the electrode, being pulled by the heme-c subunit. As a result of such electrostatic attraction, the orientation of the enzyme units would become ideal to achieve the DET from the heme-c subunit to the electrode and the chemical reaction 

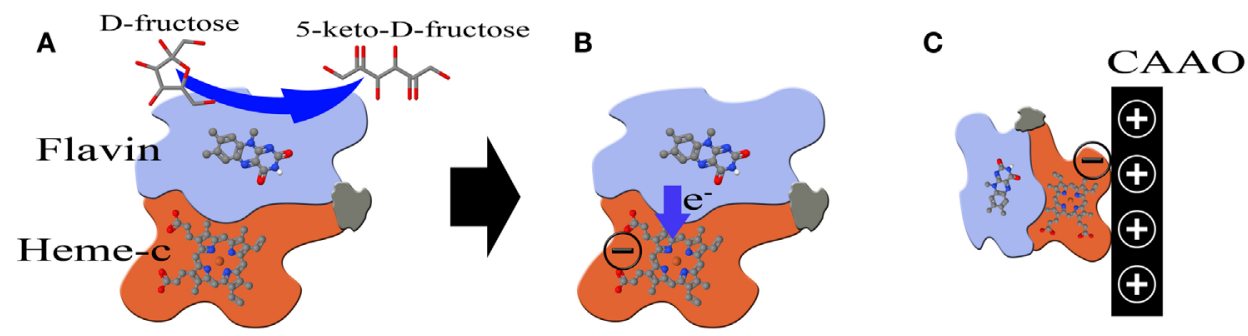

FIGURE 7 | (A) Scheme of a FDH unit and the transfer of electrons [this illustration was drawn based on Figure 9 in Tominaga et al. (2007)]. (B) Transfer of electrons from the Flavin subunit to the Heme-c one. (C) A positive potential is applied to the electrode to attract the negatively charged heme-c subunit.

sites (flavin subunits), consequently, get exposed to the fructose solution (Figure 7C).

Thus, the CAAO electrodes were soaked in the McIlvaine buffer solution $\mathrm{pH} 5$ for $1 \mathrm{~h}$ to allow the impregnation of the pores. Then, a FDH solution was added to the electrolyte and a positive potential $(0.6 \mathrm{~V}$ vs. $\mathrm{Ag} / \mathrm{AgCl})$ was applied to the CAAO. After $5 \mathrm{~min}$, an aliquot of $3 \mathrm{M} \mathrm{D}$-fructose solution was added to the mixture to obtain a final electrolyte volume of $10 \mathrm{ml}$ with a concentration of $140 \mu \mathrm{g} \mathrm{FDH} / \mathrm{ml}-200 \mathrm{mM} \mathrm{D}$-fructose (including the additives of the as-received FDH lyophilized powder, the concentration would be $3 \mathrm{mg}$ FDH/ml-200 mM D-fructose) and the potential was kept for $1 \mathrm{~h}$.

The chronoamperometry of the above system is shown in Figure $\mathbf{8}$ where two different regions can be observed. Immediately after the addition of the fructose aliquot, the current rapidly increases (zone I in Figure 8). This is probably due to the DET from FDH to the CAAO films upon the oxidation of fructose in the enzyme units that are in contact with the film surface. After this first stage, the current continuously increases (zone II in Figure 8). This second stage can be attributed to the following two different effects: (i) the FDH units are attracted to the carbon surface and (ii) the enzyme units are rearranged due to the effect of the electrostatic attraction, giving rise to a more convenient orientation of the enzymes. However, the drawback of this method is that it is not possible to measure the amount of enzymes loaded on the CAAO films with the BCA method due to the fact that $\mathrm{D}$-fructose is added to the buffer solution, i.e., the composition of the solution before and after the immobilization is different and the measurement of the concentrations with the BCA method is not reliable.

After the immobilization, the enzyme-modified CAAO electrodes were rinsed and soaked in the buffer solution $(10 \mathrm{ml})$. Then, fructose was added to the electrolyte. The resulting CV pattern shows a steeper profile with a higher oxidation current than that of the electrode prepared with the physical adsorption method (see Figure 9).

\section{Electrocatalytic Response of the Electrodes}

The CAAO electrodes loaded with FDH using both methods, namely the physical adsorption and electrostatic attraction methods, were tested individually using the electrochemical cell described above (see Figure S3 in Supplementary Material) filled

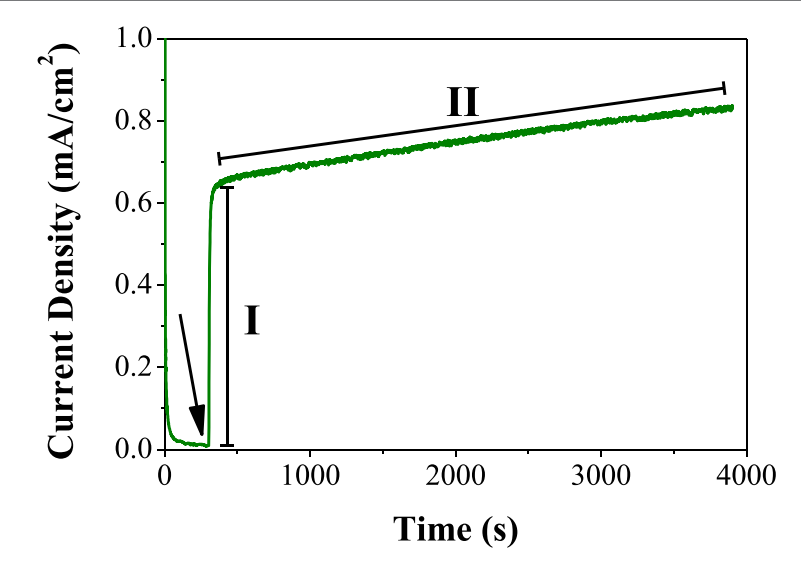

FIGURE 8 | Chronoamperometry at $0.6 \mathrm{~V}$ (vs. Ag/AgCl) of the CAAO electrodes in $\mathbf{1 4 0} \boldsymbol{\mu g} \mathbf{~ F D H / m l - 2 0 0 ~ m M ~ f r u c t o s e . ~ T h e ~ a r r o w ~ i n d i c a t e s ~ t h e ~}$ time point when the fructose was added.

with $10 \mathrm{ml}$ of McIlvaine buffer solution. Then, aliquots of $3 \mathrm{M}$ D-fructose solution prepared in the same buffer solution were added while measuring the current intensity under potentiostatic conditions ( $0.6 \mathrm{~V}$ vs. $\mathrm{Ag} / \mathrm{AgCl}$ ). Figure 10 shows the electrocatalytic current density as a function of the $\mathrm{D}$-fructose concentration in the electrolyte. As a blank measurement, a FDH-free CAAO film was tested by the same method, showing almost no catalytic current upon the addition of $\mathrm{D}$-fructose. The FDH-loaded CAAO films show a rapid increase of the current density at low fructose concentration in the electrolyte and then the currents level off after $50 \mathrm{mM}$ D-fructose. The increase of the current density upon the addition of the fructose is much faster in the case of the electrostatic attraction method. The slopes of the chronoamperometries in Figure S5 in Supplementary Material in the regions right after the first addition of the fructose aliquots were calculated to be 0.0142 and $0.0488 \mathrm{~mA} / \mathrm{s} \cdot \mathrm{cm}^{2}$ for the physical adsorption and electrostatic attraction methods, respectively (see Figure S6 in Supplementary Material). This faster response suggests that the FDH units loaded by the latter method are better oriented with respect to the surface of the pores of the CAAO films inasmuch as the films have the same physicochemical properties, and a higher loading of FDH would not explain the faster response but just a higher current density. The apparent Michaelis-Menten 


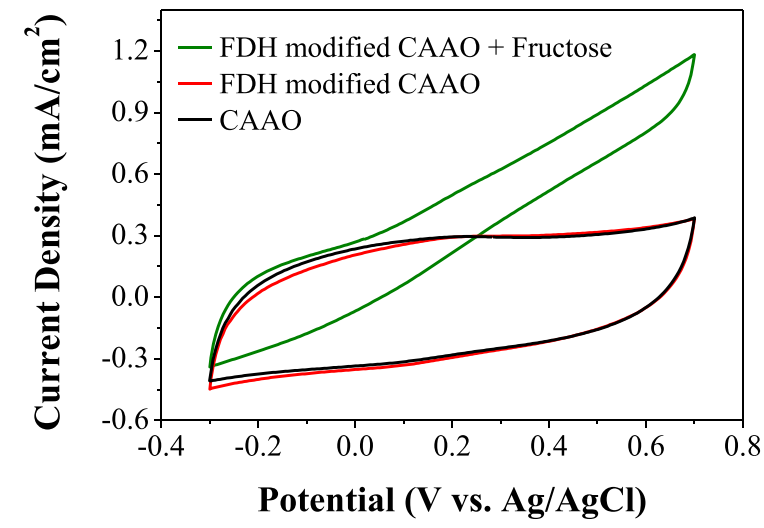

FIGURE 9 | Cyclic voltammograms of CAAO films loaded with FDH using the electrostatic attraction method.

constant $\left(K_{\mathrm{m}}\right)$ was calculated from the amperometric data using the Lineweaver-Burk type equation (Kamin and Wilson, 1980): $1 / 1=1 / 1_{\max }+K_{m} / C l_{\max }$, where $C$ is the fructose concentration. Thus, $K_{\mathrm{m}}$ is $6.9 \mathrm{mM}$ for the physical adsorption method while it drops to $2.6 \mathrm{mM}$ for the electrostatic attraction method, which indicates that the FDH immobilized on the surface of the CAAO film by the latter method shows much higher affinity for $\mathrm{D}$-fructose $\mathrm{Wu}$ et al., 2009). The maximum catalytic currents $\left(I_{\max }\right)$ obtained for the film loaded with the physical adsorption method is ca. $0.40 \mathrm{~mA} / \mathrm{cm}^{2}$. The performance is greatly improved by the electrostatic attraction method, because this method allows the catalytic current to reach ca. $0.74 \mathrm{~mA} / \mathrm{cm}^{2}$.

The effect of the pore size was evaluated by comparing the CAAO-P film (pore size: $240 \mathrm{~nm}$ ) modified with FDH using the electrostatic method. In this case, the slope of the chronoamperometry after the first addition of fructose is very similar to the one obtained for the CAAO film. The current density levels off at higher fructose concentrations (ca. $75 \mathrm{mM}$ D-fructose) and the maximum current obtained on this electrode was of ca. $0.81 \mathrm{~mA} / \mathrm{cm}^{2}$ (see Figure 10), being slightly higher than the one obtained with the CAAO film with a pore size of $40 \mathrm{~nm}$. We expected that the CAAO-P film would give a lower catalytic current. The wider the pore diameter is, the higher the individual pore surface area is, but the density of pores per electrode area is much smaller for the CAAO-P film (ca. 7.49 pores $/ \mu \mathrm{m}^{2}$ ) than that for the CAAO film (107.71 pores $/ \mu \mathrm{m}^{2}$, obtained from the SEM images, see Figure 2). Consequently, the available pore surface area is about $59 \%$ smaller than that for the CAAO film. The smaller surface area of the CAAO-P film is probably compensated with the better accessibility of the enzyme units to the larger pores, leading to the ease in enzyme immobilization, but the amount of enzyme on these films could not be estimated as explained above.

\section{CONCLUSION}

Monolithic and binderless electrodes with a large area $\left(\mathrm{ca} .1 \mathrm{~cm}^{2}\right)$ were obtained by coating anodic aluminum oxide (AAO) films with a thin layer of nitrogen-doped carbon. These films show an outstanding advantage over other porous carbon materials used as bioelectrodes,

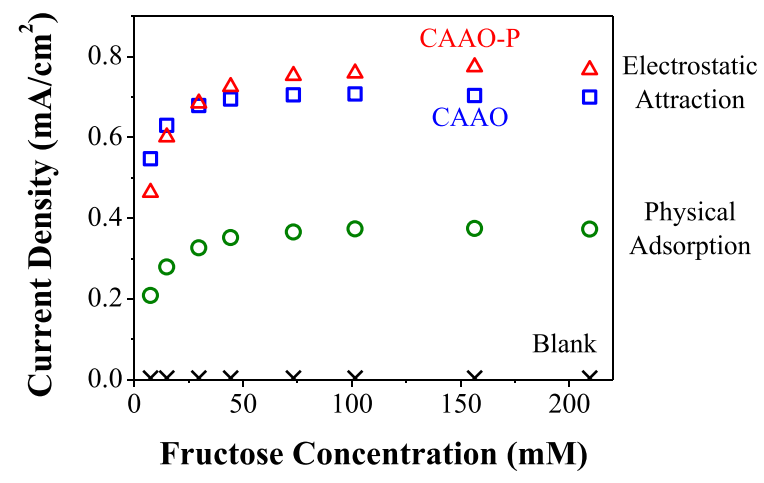

FIGURE 10 | Specific currents obtained at $0.6 \mathrm{~V}$ (vs. $\mathrm{Ag} / \mathrm{AgCl}$ ) as a function of fructose concentration for the three types of FDHmodified electrodes.

that is, the films have a very simple porous structure with straight and parallel pores that run vertically through the films ( $40 \mathrm{~nm}$ in diameter and $70 \mu \mathrm{m}$ in length). Thus, there may be no need to worry about the diffusion problem of the reactants and the products in the pores. The CAAO film was loaded with FDH enzyme with the two different methods. The first one was a simple physical adsorption, which gave a maximum current density of $0.40 \mathrm{~mA} / \mathrm{cm}^{2}$ at $0.6 \mathrm{~V}$ (vs. $\mathrm{Ag}$ / $\mathrm{AgCl}$ ) through the DET between the enzymes and the electrodes due to the catalytic oxidation of fructose. The electrochemical response of the electrodes was successfully improved by using a novel variation of the electrostatic attraction method. With this different approach, the catalytic current density is greatly increased to a maximum value of $0.74 \mathrm{~mA} / \mathrm{cm}^{2}$ at $0.6 \mathrm{~V}$ (vs. $\mathrm{Ag} / \mathrm{AgCl}$ ). Such a remarkable improvement can be attributed to an ideal molecular orientation of the FDH enzyme units on the surface of the pores, i.e., the flavin subunit where the oxidation of D-fructose to 5-keto-D-fructose takes place is exposed to the fructose solution in the pores and the heme-c subunit where the DET to the electrode occurs comes in contact with the electrode surface. This ideal orientation was achieved by attracting negatively charged heme-c subunits to the CAAO electrode to which a positive potential was applied with this new electrostatic attraction method. This method gave rise to a smaller apparent Michaelis-Menten constant, i.e., a higher affinity for $\mathrm{D}$-fructose. Moreover, the preparation of the FDH-modified electrodes using the new method takes less time, e.g., the attraction process was carried out for just $1 \mathrm{~h}$ instead of the $15 \mathrm{~h}$ for the physical adsorption method but still gives much better results. Thanks to the tunability of the diameter of the nanochannels in AAO monolithic films by modifying the preparation method, the effect of the pore size was also tested. Despite a lower surface area in the AAO film with larger pores ( $240 \mathrm{~nm}$ in diameter), they are beneficial for the enzyme immobilization, probably due to the better accessibility of the FDH macromolecules into the nanochannels.

\section{AUTHOR CONTRIBUTIONS}

AC-M: Design of experiments, acquisition of data, analysis and interpretation of data, and drafting of manuscript. YH: Study conception and design. HK: Acquisition of data. WN: Acquisition 
of data. TI: Study conception. TK: Supervision, study conception, and drafting of manuscript.

\section{ACKNOWLEDGMENTS}

AC-M acknowledges receipt of a "Clarín" postdoctoral contract from the Principado de Asturias government (Spain). This work is partially supported by AIST-Tohoku University matching

\section{REFERENCES}

Ameyama, M., Shinagawa, E., Matsushita, K., and Adachi, O. (1981). D-fructose dehydrogenase of Gluconobacter industrius: purification, characterization, and application to enzymatic microdetermination of D-fructose. J. Bacteriol. 145, 814-823.

Casanovas, J., Ricart, J. M., Rubio, J., Illas, F., and Jiménez-Mateos, J. M. (1996). Origin of the large N 1s binding energy in X-ray photoelectron spectra of calcined carbonaceous materials. J. Am. Chem. Soc. 118, 8071-8076. doi:10.1021/ ja960338m

Chen, Z., Higgins, D., and Chen, Z. (2010). Nitrogen doped carbon nanotubes and their impact on the oxygen reduction reaction in fuel cells. Carbon N. Y. 48, 3057-3065. doi:10.1016/j.carbon.2010.04.038

Filip, J., and Tkac, J. (2014). Is graphene worth using in biofuel cells? Electrochim. Acta 136, 340-354. doi:10.1016/j.electacta.2014.05.119

Flexer, V., Brun, N., Courjean, O., Backov, R., and Mano, N. (2011). Porous mediator-free enzyme carbonaceous electrodes obtained through integrative chemistry for biofuel cells. Energy Environ. Sci. 4, 2097-2106. doi:10.1039/ COEE00466A

Hamano, Y., Tsujimura, S., Shirai, O., and Kano, K. (2012). Micro-cubic monolithic carbon cryogel electrode for direct electron transfer reaction of fructose dehydrogenase. Bioelectrochemistry 88, 114-117. doi:10.1016/j. bioelechem.2012.07.005

Haneda, K., Yoshino, S., Ofuji, T., Miyake, T., and Nishizawa, M. (2012). Sheetshaped biofuel cell constructed from enzyme-modified nanoengineered carbon fabric. Electrochim. Acta 82, 175-178. doi:10.1016/j.electacta.2012.01.112

Kamin, R. A., and Wilson, G. S. (1980). Rotating ring-disk enzyme electrode for biocatalysis kinetic studies and characterization of the immobilized enzyme layer. Anal. Chem. 52, 1198-1205. doi:10.1021/ac50058a010

Kamitaka, Y., Tsujimura, S., Setoyama, N., Kajino, T., and Kano, K. (2007). Fructose/ dioxygen biofuel cell based on direct electron transfer-type bioelectrocatalysis. Phys. Chem. Chem. Phys. 9, 1793-1801. doi:10.1039/b617650j

Khan, G. F., Shinohara, H., Ikariyama, Y., and Aizawa, M. (1991). Electrochemical behaviour of monolayer quinoprotein adsorbed on the electrode surface. J. Electroanal. Chem. Interfacial Electrochem. 315, 263-273. doi:10.1016/0022-0728(91)80075-2

Lee, C.-H., Lin, T.-S., and Mou, C.-Y. (2009). Mesoporous materials for encapsulating enzymes. Nano Today 4, 165-179. doi:10.1016/j.nantod.2009.02.001

Li, A. P., Muller, F., Birner, A., Nielsch, K., and Gosele, U. (1998). Hexagonal pore arrays with a $50-420 \mathrm{~nm}$ interpore distance formed by self-organization in anodic alumina. J. Appl. Phys. 84, 6023-6026. doi:10.1063/1.368911

Lim, J., Cirigliano, N., Wang, J., and Dunn, B. (2007). Direct electron transfer in nanostructured sol-gel electrodes containing bilirubin oxidase. Phys. Chem. Chem. Phys. 9, 1809-1814. doi:10.1039/b618422g

Maldonado, S., Morin, S., and Stevenson, K. J. (2006). Structure, composition, and chemical reactivity of carbon nanotubes by selective nitrogen doping. Carbon N. Y. 44, 1429-1437. doi:10.1016/j.carbon.2005.11.027

Masuda, H., and Fukuda, K. (1995). Ordered metal nanohole arrays made by a two-step replication of honeycomb structures of anodic alumina. Science 268, 1466-1468. doi:10.1126/science.268.5216.1466 research support program 2014 and the Ministry of Education, Science, Sports and Culture, Grant-in-Aid for Scientific Research (A), 23241039.

\section{SUPPLEMENTARY MATERIAL}

The Supplementary Material for this article can be found online at http://journal.frontiersin.org//article/10.3389/fmats.2016.00007

Miyake, T., Haneda, K., Yoshino, S., and Nishizawa, M. (2013). Flexible, layered biofuel cells. Biosens. Bioelectron. 40, 45-49. doi:10.1016/j.bios.2012.05.041

Miyake, T., Yoshino, S., Yamada, T., Hata, K., and Nishizawa, M. (2011). Selfregulating enzyme-nanotube ensemble films and their application as flexible electrodes for biofuel cells. J. Am. Chem. Soc. 133, 5129-5134. doi:10.1021/ ja111517e

Pels, J. R., Kapteijn, F., Moulijn, J. A., Zhu, Q., and Thomas, K. M. (1995). Evolution of nitrogen functionalities in carbonaceous materials during pyrolysis. Carbon N. Y. 33, 1641-1653. doi:10.1016/0008-6223(95)00154-6

Rubenwolf, S., Strohmeier, O., Kloke, A., Kerzenmacher, S., Zengerle, R., and von Stetten, F. (2010). Carbon electrodes for direct electron transfer type laccase cathodes investigated by current density-cathode potential behavior. Biosens. Bioelectron. 26, 841-845. doi:10.1016/j.bios.2010.05.008

Tominaga, M., Nomura, S., and Taniguchi, I. (2009). D-Fructose detection based on the direct heterogeneous electron transfer reaction of fructose dehydrogenase adsorbed onto multi-walled carbon nanotubes synthesized on platinum electrode. Biosens. Bioelectron. 24, 1184-1188. doi:10.1016/j. bios.2008.07.002

Tominaga, M., Shirakihara, C., and Taniguchi, I. (2007). Direct heterogeneous electron transfer reactions and molecular orientation of fructose dehydrogenase adsorbed onto pyrolytic graphite electrodes. J. Electroanal. Chem. 610, 1-8. doi:10.1016/j.jelechem.2007.06.014

Toyobo-Enzymes. (0000). D-Fructose Dehydrogenase. Available at: http://www. toyobo.co.jp/seihin/xr/enzyme/j_top.html

Tsujimura, S., Nishina, A., Hamano, Y., Kano, K., and Shiraishi, S. (2010). Electrochemical reaction of fructose dehydrogenase on carbon cryogel electrodes with controlled pore sizes. Electrochem. commun. 12, 446-449. doi:10.1016/j.elecom.2010.01.016

Willner, I., Yan, Y. M., Willner, B., and Tel-Vered, R. (2009). Integrated enzyme-based biofuel cells - a review. Fuel Cells 9, 7-24. doi:10.1002/ fuce. 200800115

Wu, X., Zhao, F., Varcoe, J. R., Thumser, A. E., Avignone-Rossa, C., and Slade, R. C. T. (2009). A one-compartment fructose/air biological fuel cell based on direct electron transfer. Biosens. Bioelectron. 25, 326-331. doi:10.1016/j. bios.2009.07.011

Wu, X. E., Guo, Y.Z., Chen, M. Y., and Chen, X. D. (2013). Fabrication of flexible and disposable enzymatic biofuel cells. Electrochim. Acta 98, 20-24. doi:10.1016/j. electacta.2013.03.024

Conflict of Interest Statement: The authors declare that the research was conducted in the absence of any commercial or financial relationships that could be construed as a potential conflict of interest.

Copyright (C) 2016 Castro-Muñiz, Hoshikawa, Komiyama, Nakayama, Itoh and Kyotani. This is an open-access article distributed under the terms of the Creative Commons Attribution License (CC BY). The use, distribution or reproduction in other forums is permitted, provided the original author(s) or licensor are credited and that the original publication in this journal is cited, in accordance with accepted academic practice. No use, distribution or reproduction is permitted which does not comply with these terms. 